\title{
An Analytical Model for Predicting the Stress Distributions within Single-Lap Adhesively Bonded Beams
}

\author{
Xiaocong He and Yuqi Wang \\ Innovative Manufacturing Research Centre, Kunming University of Science and Technology, Kunming 650500, China \\ Correspondence should be addressed to Xiaocong He; hhxxcc@yahoo.co.uk
}

Received 13 November 2013; Accepted 23 December 2013; Published 11 February 2014

Academic Editor: Filippo Berto

Copyright (C) 2014 X. He and Y. Wang. This is an open access article distributed under the Creative Commons Attribution License, which permits unrestricted use, distribution, and reproduction in any medium, provided the original work is properly cited.

\begin{abstract}
An analytical model for predicting the stress distributions within single-lap adhesively bonded beams under tension is presented in this paper. By combining the governing equations of each adherend with the joint kinematics, the overall system of governing equations can be obtained. Both the adherends and the adhesive are assumed to be under plane strain condition. With suitable boundary conditions, the stress distribution of the adhesive in the longitudinal direction is determined.
\end{abstract}

\section{Introduction}

The use of adhesively bonded joint, which uses metallic, composite, and ceramic materials, is of great interest to many industrial sectors including aerospace, automotive, marine, machine tools, package, and appliance industries. This widespread use of adhesive joints is due to ease of application, time and cost savings, high corrosion and fatigue resistance, crack retardance, and good damping characteristics [1-3].

Any joint occurring in practice is designed to carry a given set of loads. Most of the adherends are loaded in tension. The subsequent loads on the adhesive are then a function of the geometry of the joint. Under most operating loads and environmental conditions, the adherends behave in a linearly elastic manner. However, the adhesive may exhibit viscoelastic or nonlinear behaviour. The exact analytical solution to the problem of stress distributions in the bonded area is complex. The existing analytical studies are, therefore, based on certain simplifying assumptions with regard to the modelling of the adhesive and adherends.

In Volkersen's shear-lag analysis, it was assumed that the adhesive deforms only in shear, while the adherend deformed only in tension [4]. The consequences of the rotation of the adherends were first taken into account by Goland and Reissner [5]. The authors derived equations to evaluate the shearing and normal stresses in the bond layer as well as those in the jointed plates, assuming that the peel and shear stresses were constants across the adhesive thickness. In Cornell's work [6], a variation and extension of Goland and Reissner's method were presented for determining the stresses in adhesive lap joints. The author assumed that the two lap joint plates act like simple beam and the more elastic adhesive layer is an infinite number of shear and tension springs. Differential equations were set up which describe the transfer of the load in one beam through the springs to the other beam. From the solution of these differential equations a fairly complete analysis of the stresses in the lap joint was obtained.

Ojalvo and Eidinoff [7] presented results of an analytical investigation on the influence of bond thickness upon the stress distribution in single adhesive lap joints. The work extended the basic approach for bonded joints, originally introduced by Goland and Reissner, through the use of a more complete shear-strain/displacement equation for the adhesive layer. The work uncovers several interesting phenomena without adding any significant complication to the analysis. Delale et al. [8] analyzed a general plane strain problem of adhesively bonded structures which consist of two different orthotropic adherends. Both the transverse shear stress effects in the adherends and the in-plane normal strain in the adhesive were taken into account. The solution was 


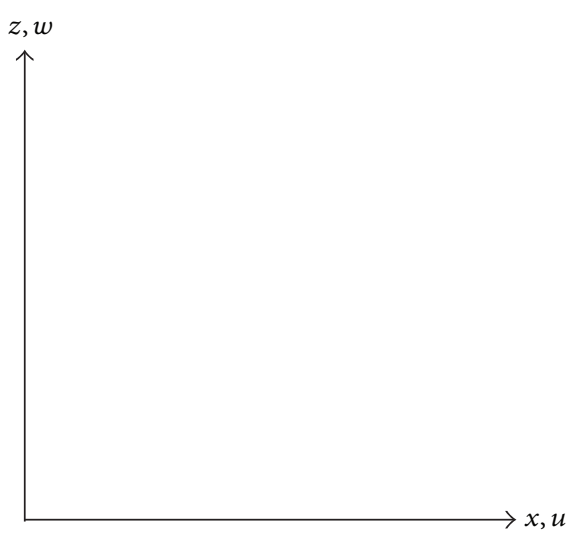

Figure 1: Coordinate system.

obtained by assuming linear stress-strain relations for the adhesive. The peak values of the shear as well as those of the normal stress in the adhesive were found to be at the edges of the overlap region. Rossettos et al. [9] established the governing equations for a step lap joint with a void using a modified shear-lag model, where the adhesive can have extensional as well as shear deformations. The model considers quadratic axial deformation across the adhesive thickness.

The objective of this work is to present an analytical model for predicting the stress distributions within a singlelap adhesively bonded beam under tension. This model is a development of the shear-lag analysis model of Volkersen [4]. The derivations are similar to those of Goland and Reissner [5] but the geometry employed is different. By combining the governing equations of each adherend with the joint kinematics, the overall system of governing equations can be obtained. Both the adherends and the adhesive are assumed to be under plane strain condition, and the adhesive stresses are assumed to be uniform across the thickness. With suitable boundary conditions, the stress distribution of the adhesive in the longitudinal direction is determined.

\section{Formulation of the Problem}

Figure 1 shows the coordinate system used in this study; $x$ and $z$ are coordinates, while $u$ and $w$ represent displacements. A single-lap-jointed beam is shown in Figure 2. The joint length is $2 c$. The two adherends are considered to be of equal thickness $t$ and equal length $(l+2 c)$. Two points $a$ and $b$ are the points at the centre of two free edge of the single-lapjointed beam. The adhesive thickness is $\eta$. The joint width is assumed to be large compared with the adherend thickness. If the system is now loaded by tensile forces $T$ per unit of adherend width at the points $a$ and $b$, the line of action of the forces will be $a o b$.

For studying the system deformation, two coordinate systems $\left(x_{1}, z_{1}\right)$ and $\left(x_{2}, z_{2}\right)$ are introduced in Figure 2. The first system is used to analyze the behavior of the lefthand adherend under load. The coordinate $x_{1}$ has its origin at the point $a$, extends along the longitudinal axis of the adherend, and is positive to the right. $w_{1}$ represents transverse deformation of the adherend from the unloaded condition and is positive upwards. A similar definition is taken for $\left(x_{2}, z_{2}\right)$ with reference to the joint.

If $M_{1}$ is equal to the bending moment in the adherend at station $x_{1}$ and $M_{2}$ is equal to the moment in the joint at station $x_{2}$, each per unit of width, then

$$
\begin{gathered}
M_{1}=T\left[\tan \alpha_{n} x_{1}-w_{1}\right] \quad\left(0 \leq x_{1} \leq l\right), \\
M_{2}=T\left[\tan \alpha_{n}\left(l+x_{2}\right)-w_{2}-\frac{t+\eta}{2}\right] \quad\left(0 \leq x_{2} \leq c\right),
\end{gathered}
$$

where

$$
\tan \alpha_{n}=\frac{(t+\eta) / 2}{l+c}
$$

As $\eta \ll t$ and $t \ll l$,(1) then reduce to the simplified forms by using Taylor series:

$$
\begin{gathered}
M_{1}=T\left[\alpha_{n} x_{1}-w_{1}\right] \quad\left(0 \leq x_{1} \leq l\right), \\
M_{2}=T\left[\alpha_{n}\left(l+x_{2}\right)-w_{2}-\frac{t}{2}\right] \quad\left(0 \leq x_{2} \leq c\right) .
\end{gathered}
$$

As for deformations $w_{1}$ and $w_{2}$, we have

$$
\begin{aligned}
& \frac{d^{2} w_{1}}{d x_{1}^{2}}=-\frac{M_{1}}{D_{1}}, \\
& \frac{d^{2} w_{2}}{d x_{2}^{2}}=-\frac{M_{2}}{D_{2}},
\end{aligned}
$$

where $D_{1}$ and $D_{2}$ are the flexural rigidities of the adherend and joint, respectively.

From (3) and (4), we have

$$
\begin{gathered}
\frac{d^{2} w_{1}}{d x_{1}^{2}}=-\frac{T}{D_{1}}\left[\alpha_{n} x_{1}-w_{1}\right] \quad\left(0 \leq x_{1} \leq l\right), \\
\frac{d^{2} w_{2}}{d x_{2}^{2}}=-\frac{T}{D_{2}}\left[\alpha_{n}\left(l+x_{2}\right)-w_{2}-\frac{t}{2}\right] \quad\left(0 \leq x_{2} \leq c\right) .
\end{gathered}
$$

From the four boundary conditions

$$
\begin{gathered}
\text { at } x_{1}=0, \quad w_{1}=0, \\
\text { at } x_{1}=l, \quad x_{2}=0, \quad w_{1}=w_{2}, \\
\text { at } x_{1}=l, \quad x_{2}=0, \quad \frac{d w_{1}}{d x_{1}}=\frac{d w_{2}}{d x_{2}}, \\
\text { at } x_{2}=c, \quad w_{2}=0 .
\end{gathered}
$$

The two preceding equations (5) and (6) have solutions of the form

$$
\begin{array}{r}
w_{1}=A_{1} \cosh b_{1} x_{1}+B_{1} \sinh b_{1} x_{1}+\alpha_{n} x_{1} \quad\left(0 \leq x_{1} \leq l\right), \\
w_{2}=A_{2} \cosh b_{2} x_{2}+B_{2} \sinh b_{2} x_{2}+\alpha_{n}\left(l+x_{2}-\frac{t}{2}\right) \\
\left(0 \leq x_{2} \leq c\right)
\end{array}
$$




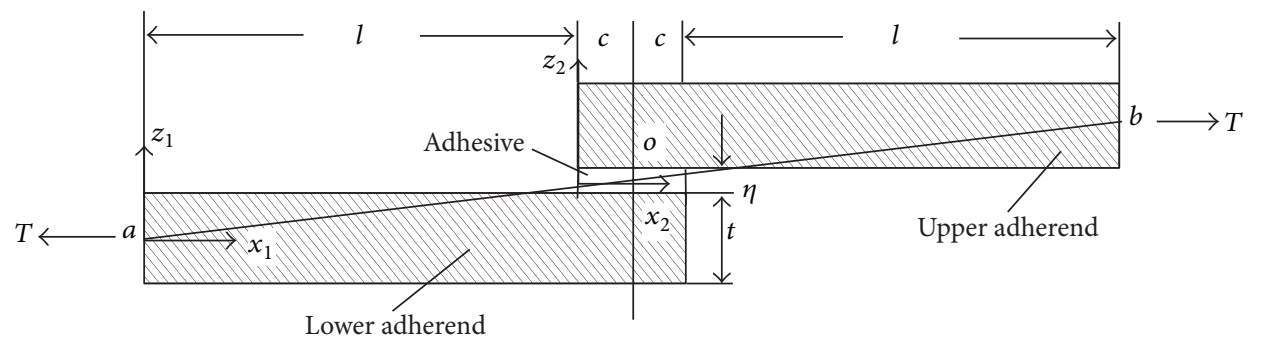

Figure 2: A single-lap-jointed beam.

where [5]

$$
\begin{gathered}
A_{1}=\frac{-(t / 2) \sinh \left(b_{2} c\right)}{\sinh \left(b_{1} l\right) \cosh \left(b_{2} c\right)+\left(b_{2} / b_{1}\right) \sinh \left(b_{1} l\right) \cosh \left(b_{2} c\right)}, \\
A_{2}=\frac{(t / 2)\left(b_{2} / b_{1}\right) \cosh \left(b_{1} l\right) \sinh \left(b_{2} c\right)}{\sinh \left(b_{1} l\right) \cosh \left(b_{2} c\right)+\left(b_{2} / b_{1}\right) \sinh \left(b_{1} l\right) \cosh \left(b_{2} c\right)}, \\
B_{1}=\frac{-(t / 2) \cosh \left(b_{2} c\right)}{\sinh \left(b_{1} l\right) \cosh \left(b_{2} c\right)+\left(b_{2} / b_{1}\right) \sinh \left(b_{1} l\right) \cosh \left(b_{2} c\right)}, \\
B_{2}=\frac{(t / 2)\left(b_{2} / b_{1}\right) \cosh \left(b_{1} l\right) \cosh \left(b_{2} c\right)}{\sinh \left(b_{1} l\right) \cosh \left(b_{2} c\right)+\left(b_{2} / b_{1}\right) \sinh \left(b_{1} l\right) \cosh \left(b_{2} c\right)}, \\
b_{1}^{2}=\frac{T}{D_{1}}, \\
b_{2}^{2}=\frac{T}{D_{2}} .
\end{gathered}
$$

\section{Stress Distributions in the Adhesive Layer}

Figure 3 shows elements of the upper and lower adherends. $M, V$, and $T$ are the bending moments, vertical shear, and axial tension in the adherends. The subscripts $u$ and $l$ designate quantities pertaining to the upper and lower adherend, respectively. $\sigma_{0}$ and $\tau_{0}$ are the transverse normal stress and the shear stress, respectively.

The conditions of moment equilibrium for the elements of the adherends are

$$
\begin{aligned}
& \frac{d M_{u}}{d x}-V_{u}+\tau_{0} \frac{t}{2}=0, \\
& \frac{d M_{l}}{d x}-V_{l}+\tau_{0} \frac{t}{2}=0 .
\end{aligned}
$$

The conditions of horizontal force equilibrium are

$$
\begin{aligned}
& \frac{d T_{u}}{d x}-\tau_{0}=0, \\
& \frac{d T_{l}}{d x}+\tau_{0}=0 .
\end{aligned}
$$

The conditions of vertical force equilibrium for the elements of the adherends are

$$
\begin{aligned}
& \frac{d V_{u}}{d x}-\sigma_{0}=0, \\
& \frac{d V_{l}}{d x}+\sigma_{0}=0 .
\end{aligned}
$$

The transverse deflections of the upper and lower adherends are denoted by $v_{u}$ and $v_{l}$, respectively, both measured positively upward. Then the thin plate theory gives

$$
\begin{gathered}
\frac{d^{2} v_{u}}{d x^{2}}=-\frac{M_{u}}{D_{1}}, \\
\frac{d^{2} v_{l}}{d x^{2}}=-\frac{M_{l}}{D_{1}}, \\
\text { with } D_{1}=\frac{E t^{3}}{12\left(1-v^{2}\right)},
\end{gathered}
$$

where $E$ and $v$ are Young's modulus and Poisson's ratio of adherends, respectively. $D_{1}$ refers to the flexural rigidity of the adherends.

The longitudinal displacements of the adherend at the adherend boundaries adjacent to the adhesive are denoted by $u_{u}$ and $u_{l}$. Then from the stress-strain relations

$$
\begin{aligned}
\frac{d u_{u}}{d x} & =\frac{1}{E}\left(\frac{T_{u}}{t}-6 \frac{M_{u}}{t^{2}}\right), \\
\frac{d u_{l}}{d x} & =\frac{1}{E}\left(\frac{T_{l}}{t}+6 \frac{M_{l}}{t^{2}}\right) .
\end{aligned}
$$

Let $E_{a d}$ and $G_{a d}$ refer to Young's and shear moduli, respectively, of the adhesive material; then

$$
\begin{gathered}
\frac{\tau_{0}}{G_{a d}}=\frac{u_{u}-u_{l}}{\eta}, \\
\frac{\sigma_{0}}{E_{a d}}=\frac{v_{u}-v_{l}}{\eta} .
\end{gathered}
$$

Combining equations from (10) to (14) and differentiating equation (15) we have

$$
\begin{gathered}
\frac{d^{3} \tau_{0}}{d x^{3}}-\frac{8 G_{a d}}{E t \eta} \frac{d \tau_{0}}{d x}=0, \\
\frac{d^{4} \sigma_{0}}{d x^{4}}+\frac{24\left(1-v^{2}\right) E_{a d}}{E t^{3} \eta} \sigma_{0}=0 .
\end{gathered}
$$




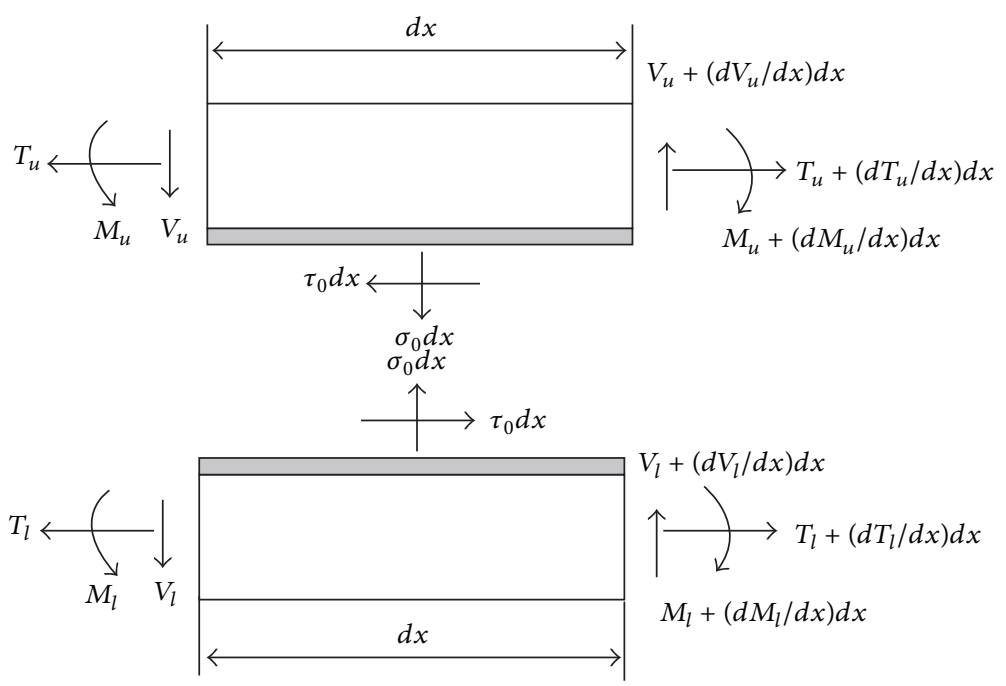

FIGURE 3: Free body diagram of joint with adhesive layer.

The boundary conditions can be written as

$$
\begin{array}{cc}
\text { at } x=c, & M_{u}=T_{u}=V_{u}=0, \\
M_{l}=M_{0}, & V_{l}=V_{0}, \quad T_{l}=T, \\
\text { at } x=-c, & M_{l}=T_{l}=V_{l}=0, \\
M_{u}=-M_{0}, & V_{u}=V_{0}, \quad T_{u}=T .
\end{array}
$$

From (8) and (9) we have

$$
\begin{gathered}
M_{0}=\left(M_{1}\right)_{x_{1}=l}=-D_{1}\left(\frac{d^{2} w_{1}}{d x_{1}^{2}}\right)_{x_{1}=l}=k \frac{T t}{2}, \\
V_{0}=\left(\frac{d M_{1}}{d x_{1}}\right)_{x_{1}=l}=k T\left[3\left(1-v^{2}\right) \frac{T}{E t}\right]^{1 / 2}, \\
k=\frac{\sinh \left(b_{1} l\right) \cosh \left(b_{2} c\right)}{\sinh \left(b_{1} l\right) \cosh \left(b_{2} c\right)+\left(b_{1} / b_{2}\right) \cosh \left(b_{1} l\right) \sinh \left(b_{2} c\right)} .
\end{gathered}
$$

On the basis of the differential equations (16) and (17) and the boundary conditions, the distributions of $\sigma_{0}$ and $\tau_{0}$ in the adhesive are obtained in the form

$$
\begin{gathered}
\sigma_{0}=\frac{p t^{2}}{\Delta c^{2}}\left[\left(R_{2} \lambda^{2} \frac{k}{2}+\lambda k^{\prime} \cosh \lambda \cos \lambda\right) \cosh \lambda \frac{x}{c} \cos \lambda \frac{x}{c}\right. \\
\left.+\left(R_{1} \lambda^{2} \frac{k}{2}+\lambda k^{\prime} \sinh \lambda \sin \lambda\right) \sinh \lambda \frac{x}{c} \sin \lambda \frac{x}{c}\right] \\
\tau_{0}=-\frac{p t}{8 c}\left[\frac{\beta c}{t}(1+3 k) \frac{\cosh (\beta x / t)}{\sinh (\beta c / t)}+3(1-k)\right]
\end{gathered}
$$

where

$$
\begin{gathered}
\lambda=\gamma \frac{c}{t}, \quad \gamma^{4}=6 \frac{E_{a d}}{E} \frac{t}{\eta}, \quad \beta^{2}=8 \frac{G_{a d}}{E} \frac{t}{\eta}, \\
R_{1}=\cosh \lambda \sin \lambda+\sinh \lambda \cos \lambda, \\
R_{2}=\sinh \lambda \cos \lambda-\cosh \lambda \sin \lambda, \\
\Delta=\frac{1}{2}(\sinh 2 \lambda+\sin 2 \lambda), \quad k=\frac{2 M_{0}}{p t^{2}}, \quad k^{\prime}=\frac{V_{0} c}{p t^{2}},
\end{gathered}
$$

$$
b_{1}=2\left[\frac{3 p\left(1-v^{2}\right)}{E t^{2}}\right]^{1 / 2}, \quad b_{2}=\frac{b_{1}}{2 \sqrt{2}} .
$$

If the materials and the thickness of the adherends are different, then (17) may become a 7th order differential equation. It is obvious that the analytical model is very complex and only the stress distributions of the adhesive in the longitudinal direction are determined. In addition, the adhesive stresses actually are not uniform across the thickness. In other words, the simplifications have restricted the results. Usually, when we consider different boundary conditions by a closed-form analysis, the limitation is how tractable a realistic mathematical model is within an algebraic solution. To overcome this limitation, the finite element analysis (FEA) technique can be employed.

\section{Summary}

An analytical model was presented for predicting the stress distributions within a single-lap adhesively bonded beam under tension. By combining the governing equations of each adherend with the joint kinematics, the overall system of governing equations can be obtained. Both the adherends and the adhesive are assumed to be under plane strain condition, and the adhesive stresses are assumed to be uniform across the thickness. With suitable boundary conditions, the stress 
distribution of the adhesive in the longitudinal direction is determined.

\section{Conflict of Interests}

The authors declare that there is no conflict of interests regarding the publication of this paper.

\section{Acknowledgment}

This study is partially supported by the Special Program of the Ministry of Science and Technology, China (Grant no. 2012ZX04012-031).

\section{References}

[1] X. He, "A review of finite element analysis of adhesively bonded joints," International Journal of Adhesion and Adhesives, vol. 31, no. 4, pp. 248-264, 2011.

[2] X. He, F. Gu, and A. Ball, "Fatigue behaviour of fastening joints of sheet materials and finite element analysis," Advances in Mechanical Engineering, vol. 2013, Article ID 658219, 9 pages, 2013.

[3] X. He, "Finite element analysis of torsional free vibration of adhesively bonded single-lap joints," International Journal of Adhesion and Adhesives, vol. 48, pp. 59-66, 2014.

[4] O. Volkersen, "Die Nietkraftverteilung in Zugbeanspruchten Nietverbindungen mit Konstanten Laschenquerschnitten," Luftfarhtforschung, vol. 15, pp. 41-47, 1938.

[5] M. Goland and E. Reissner, "Stresses in cemented joints," Journal of Applied Mechanics, vol. 11, pp. A17-A27, 1944.

[6] R. W. Cornell, "Determination of stresses in cemented lap joints," Journal of Applied Mechanics, vol. 20, pp. 355-364, 1953.

[7] I. U. Ojalvo and H. L. Eidinoff, "Bond thickness effects upon stresses in single-lap adhesive joints," AIAA Journal, vol. 16, no. 3, pp. 204-211, 1978.

[8] F. Delale, F. Erdogan, and M. N. Aydinoglu, "Stress in adhesively bonded joints: a closed-form solution," Journal of Composite Materials, vol. 15, no. 3, pp. 249-271, 1981.

[9] J. N. Rossettos, P. Lin, and H. Nayeb-Hashemi, "Comparison of the effects of debonds and voids in adhesive joints," Journal of Engineering Materials and Technology, vol. 116, no. 4, pp. 533$538,1994$. 

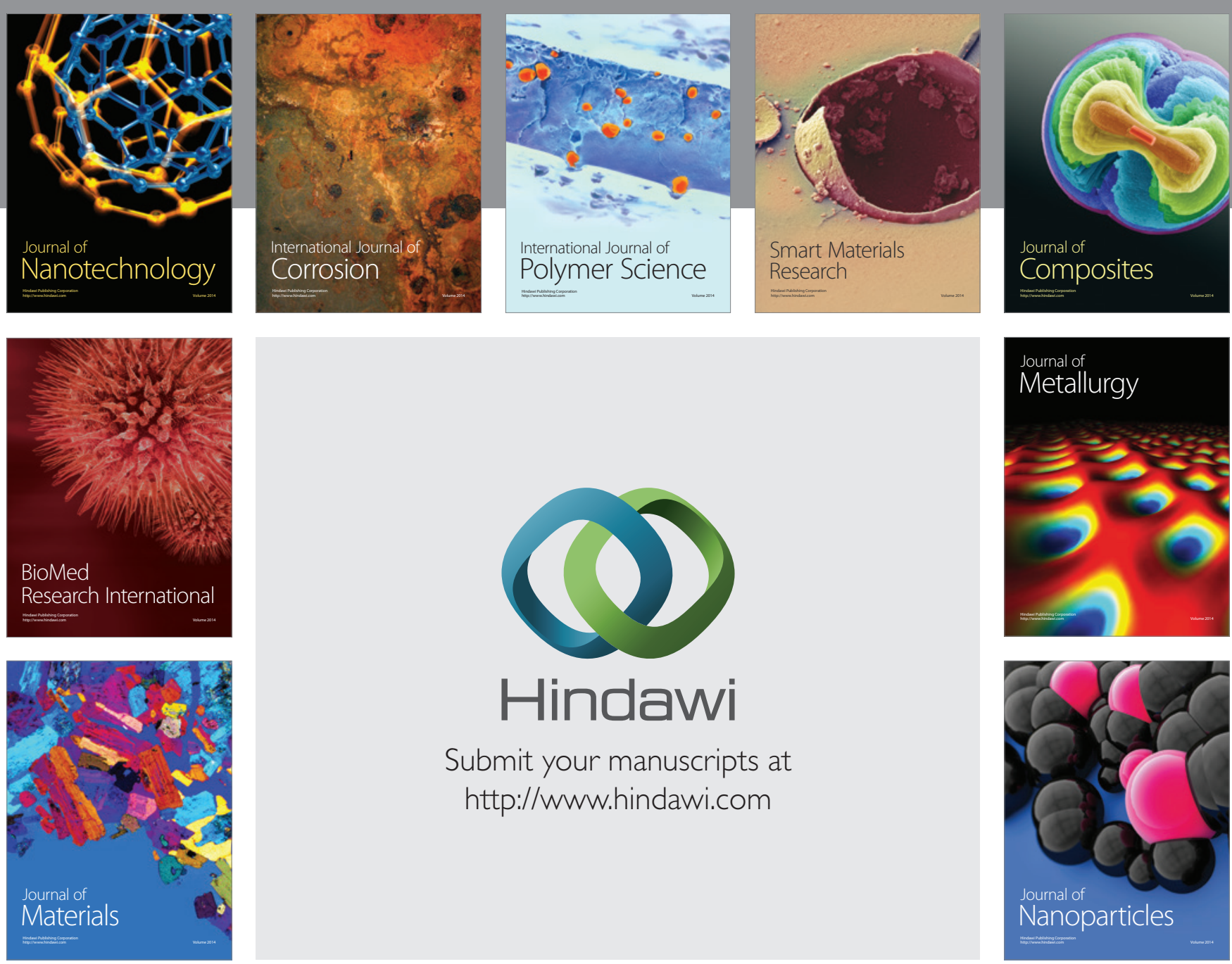

Submit your manuscripts at http://www.hindawi.com
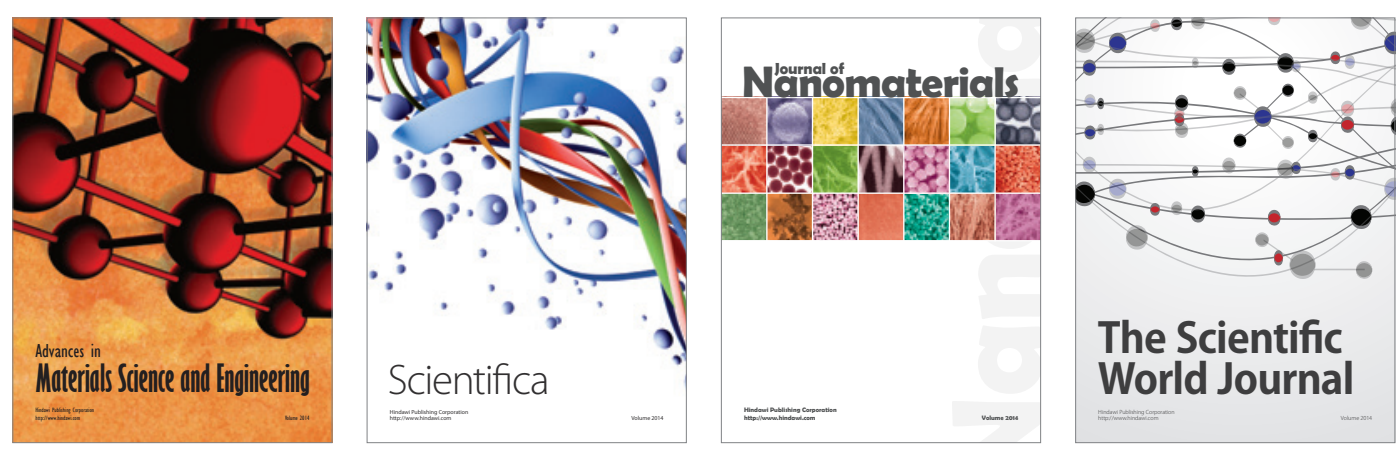

\section{The Scientific World Journal}
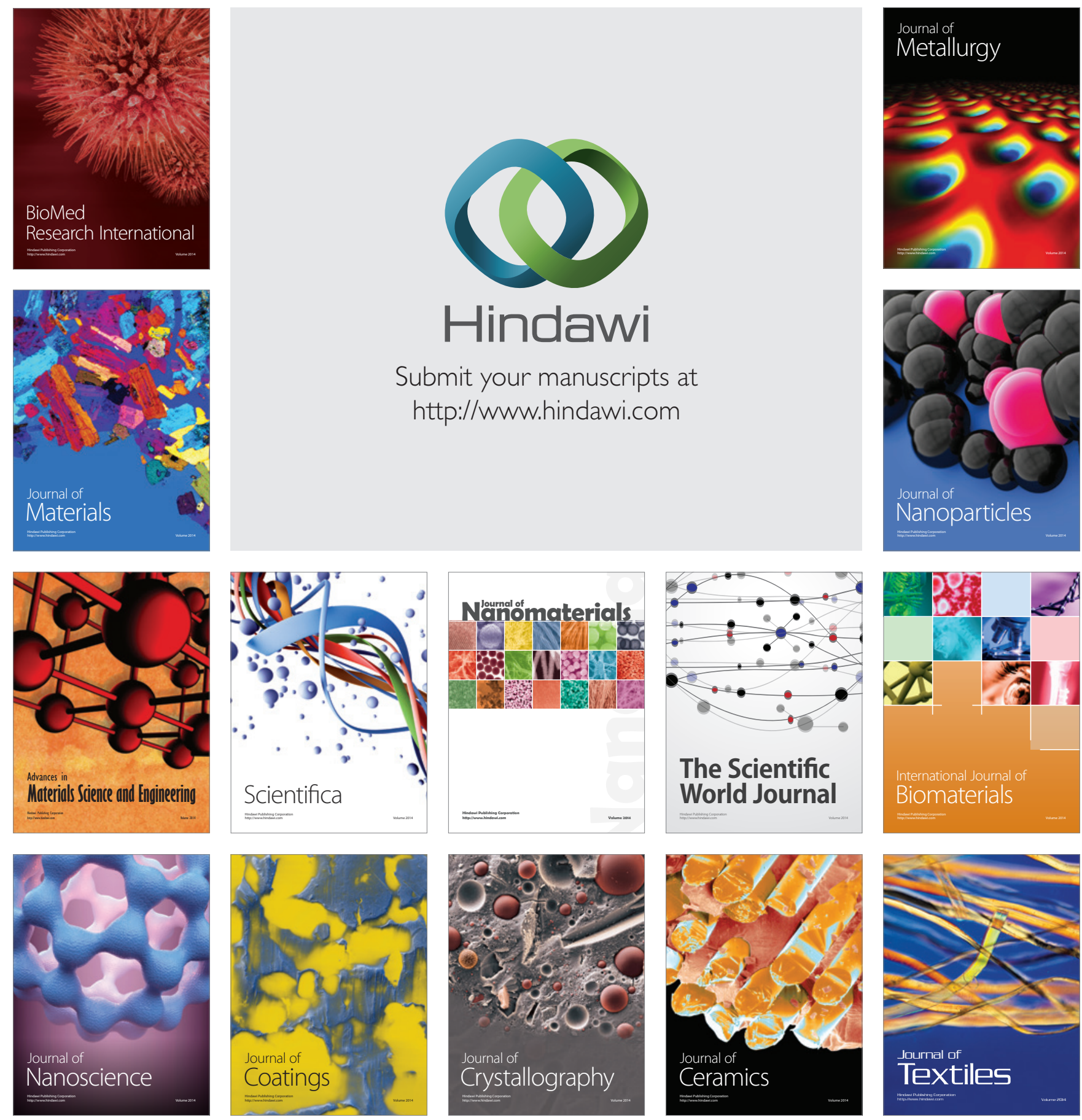